SHORT REPORT

\title{
Development of molecular methods for the identification of aspergillus and emerging moulds in paraffin wax embedded tissue sections
}

\author{
P J Paterson, S Seaton, J McLaughlin, C C Kibbler
}

J Clin Pathol: Mol Pathol 2003;56:368-370

Background/Aims: Invasive infection with emerging moulds is increasing in incidence and reliable methods for speciating these organisms in tissue sections need to be developed.

Methods: Two methods for extracting fungal DNA from paraffin wax embedded tissue sections, based on the TaKaRa DEXPAT ${ }^{T M}$ kit and QIAamp ${ }^{\circledR}$ DNA mini kit, were optimised and compared. DNA was amplified by PCR using pan-fungal probes, and detected by Southern blot hybridisation using a high stringency method with a probe specific for Aspergillus fumigatus and A flavus.

Results: The method based on the TaKaRa DEXPAT kit, with additional steps using lyticase and ethanol precipitation, was superior. Less than 10 conidia were detectable using spiked samples and a positive result was obtained with $100 \%$ of clinical samples known to be culture positive for $A$ fumigatus. Other moulds could be identified by using species specific probes or by sequencing PCR products.

Conclusions: The method based on the TaKaRa DEXPAT kit could detect less than 10 conidia/sample. The method allowed accurate identification of $A$ fumigatus and $A$ flavus and other species could be identified using species specific probes or by DNA sequencing. These methods will provide a valuable diagnostic tool for both patient management and future antifungal and epidemiological studies.

\footnotetext{
A lthough aspergillus remains the most common cause of invasive fungal infections (IFIs), the range of moulds causing this disease in immunosuppressed patients is increasing. ${ }^{1}$ Confirmation of the diagnosis of IFI requires histological evidence of tissue invasion by fungal hyphae. However, many moulds resemble aspergillus species histologically, and accurate identification relies on culturing the organism from the tissue. We have previously reported that culture from histologically positive tissues is only positive in $54 \%$ of cases $^{2}$ and, therefore, the development of other methods is clearly required.

The aim of our study was to establish a method to speciate fungal pathogens in paraffin wax tissue sections, using the polymerase chain reaction (PCR) and Southern blot hybridisation.
}

\section{MATERIALS AND METHODS}

\section{Spiked tissue samples}

Tenfold serial dilutions ( $10^{4}$ to $10^{0}$ conidia/ $10 \mu \mathrm{l}$ solution) of Aspergillus fumigatus NCPF 7097 conidia (PHLS Mycology Reference Laboratory, Bristol, UK) and a negative control ( $10 \mu \mathrm{l}$ sterile distilled water) were used to compare the methods. Sections ( $10 \mu \mathrm{m}$ thick) of formalin fixed, paraffin wax embedded, normal human lung tissue were cut using a sterile microtome blade, with two sections used for each sample. Each method was run three times to ensure reproducibility.

\section{DNA extraction}

Method based on TaKaRa DEXPAT ${ }^{\mathrm{TM}}$ kit (TaKaRa Biomedicals, Shiga, Japan)

Three modifications to the manufacturer's methods were studied, namely:

(1) Incubation with lyticase (L5263; Sigma, Poole, Dorset, $\mathrm{UK}$; $1 \mathrm{U}, 2 \mathrm{U}$, and $5 \mathrm{U} / 100 \mu \mathrm{l}$ solution) for 45 minutes at $37^{\circ} \mathrm{C}$, following initial incubation in DEXPAT solution.

(2) Addition of $28 \mathrm{mM} \beta$ mercaptoethanol with $2 \mathrm{U} / 100 \mu \mathrm{l}$ lyticase.

(3) Ethanol precipitation of the supernatant.

Method based on QIAamp ${ }^{\circledR}$ DNA mini kit (Qiagen, Hilden, Germany)

Two modifications to the manufacturer's methods were studied, namely:

(1) Incubation with lyticase ( $1 \mathrm{U}, 2 \mathrm{U}$, and $5 \mathrm{U} / 100 \mu \mathrm{l}$ solution) for 45 minutes at $37^{\circ} \mathrm{C}$ following proteinase $\mathrm{K}$ lysis.

(2) Addition of $28 \mathrm{mM} \beta$ mercaptoethanol with $2 \mathrm{U} / 100 \mu \mathrm{l}$ lyticase.

Ethanol precipitation was not studied because DNA is separated using the QIAamp column provided.

\section{Amplification of DNA}

The pan-fungal primers and method described by Einsele et al were used. ${ }^{3}$ The number of cycles was increased from 35 to 50, which enabled the detection of $\mathrm{l} \mathrm{fg}$ of DNA after Southern blot hybridisation. A positive control containing purified A fumigatus DNA and two negative control samples were included in each run.

\section{Detection of amplification products}

PCR products were separated in a $1.8 \%$ agarose gel in Tris acetate EDTA buffer ( $\mathrm{pH} 8 ; 40 \mathrm{mM}$ Tris-acetate $(\mathrm{pH} \mathrm{7.5)}$, $2 \mathrm{mM}$ sodium EDTA). Amplicons were transferred on to a nylon membrane for Southern blotting. A DNA probe designed by Einsele et al, ${ }^{3}$ which hybridises with A fumigatus, $A$ flavus, and $A$ versicolor, was labelled using the Gene Images 3' oligolabelling module (Amersham Pharmacia Biotech,

Abbreviations: $\mathrm{IFI}$, invasive fungal infection; $\mathrm{PCR}$, polymerase chain reaction 
A

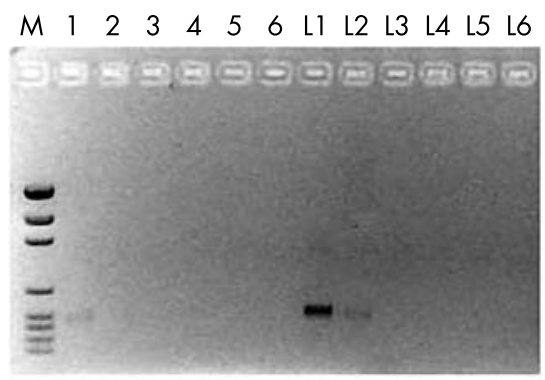

C

$\begin{array}{lllllllllllll}M & 1 & 2 & 3 & 4 & 5 & 6 & \text { L1 } & \text { L2 } & \text { L3 } & \text { L4 } & \text { L5 } & \text { L6 }\end{array}$

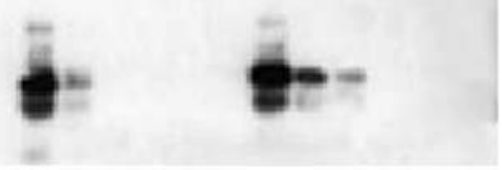

B

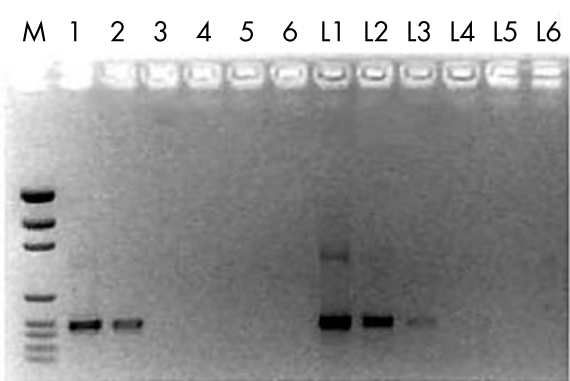

D

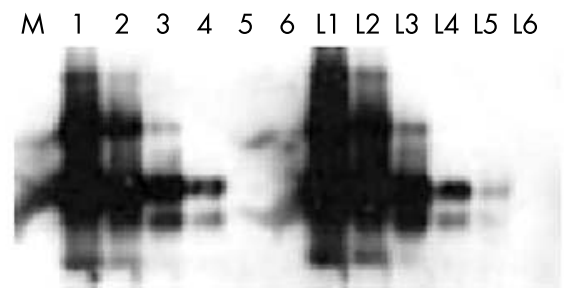

Figure 1 Comparison of methods with spiked samples. (A) Gel of QIAamp method with and without lyticase. (B) Gel of TaKaRa method plus ethanol precipitation, with and without lyticase. (C) Blot of QIAamp methods. (D) Blot of TaKaRa methods. $M$, molecular weight marker; lanes $1-5,10^{4}, 10^{3}, 10^{2}, 10^{1}$, and $10^{\circ}$ Aspergillus fumigatus conidia, respectively; lane 6, negative control. L, with lyticase.
Amersham, UK). Blots were prehybridised for 30 minutes at $65{ }^{\circ} \mathrm{C}$, then hybridised for 20 minutes at $65^{\circ} \mathrm{C}$. Three washes for 15 minutes at $76^{\circ} \mathrm{C}$ in $0.75 \mathrm{M} \mathrm{NaCl}, 0.15 \mathrm{M} \mathrm{NaH} \mathrm{PO}_{4}, 1 \%$ sodium dodecyl sulfate were performed. The Gene Images
CDP-Star detection module (Amersham Pharmacia Biotech) was used.

DNA samples from A flavus, A niger, A terreus, Candida albicans, Fusarium oxysporum, Scedosporium apiospermum,
A

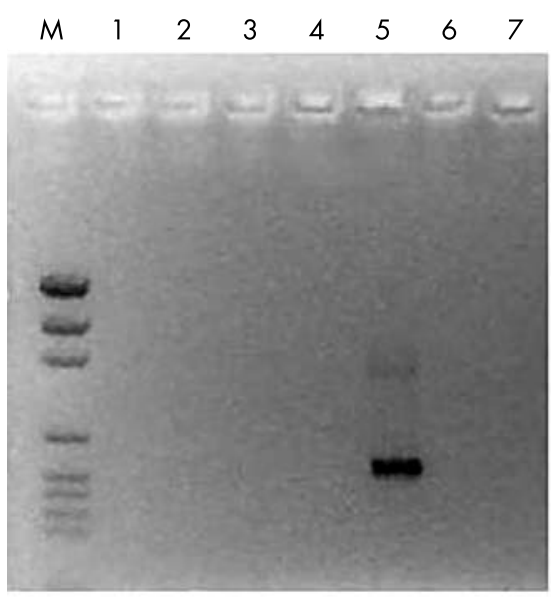

C

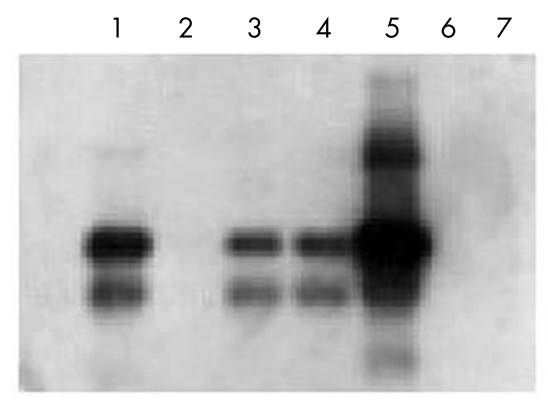

B

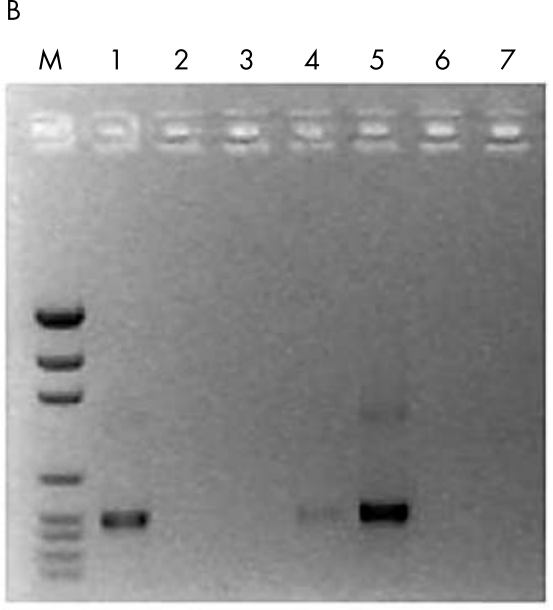

Figure 2 Comparison of methods with clinical samples. (A) Gel of QIAamp method. (B) Gel of TaKaRa method. (C) Blot of QIAamp method. (D) Blot of TaKaRa method. M, molecular weight marker; lanes 1-5, clinical samples 15 , respectively; lanes 6 and 7 , negative controls.
D

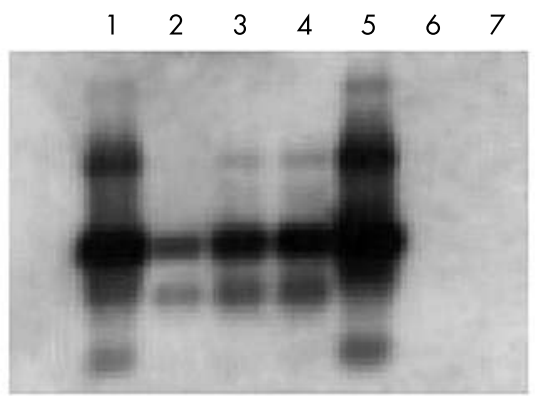




\section{Take home messages}

- There is a need for the development of methods other than culture for the speciation of fungal pathogens in clinical samples

- We optimised and compared two molecular methods and found that one based on the TaKaRa DEXPAT kit, with the addition of lyticase and ethanol precipitation of extracted DNA, was the most sensitive

- This method could detect less than 10 conidia/sample and allowed accurate identification of $A$ fumigatus and A flavus

- Other species could be identified using other species specific probes or by DNA sequencing

Toxoplasma gondii, Mycobacterium tuberculosis, cytomegalovirus, Pneumocystis carinii, and Streptococcus pneumoniae were used as controls.

\section{Clinical tissue samples}

Five clinical lung tissue specimens, which were both histologically and culture positive for A fumigatus, were identified. These specimens had been stored for up to 10 years in the pathology department. Sections (10 $\mu \mathrm{m}$ thick) were cut using a sterile blade for each specimen. Two sections were used for each sample.

\section{RESULTS}

Optimisation and comparison using spiked samples (fig 1)

Initial results with the QIAamp DNA mini kit (sensitivity, $10^{4}$ conidia) were superior to the TaKaRa DEXPAT kit $\left(\right.$ sensitivity, $>10^{4}$ ) (results not shown). Lyticase (2 U/ $100 \mu \mathrm{l})$ increased the sensitivity with the QIAamp based method (sensitivity, $10^{3}$ conidia). Results with the TaKaRa based method were improved by ethanol precipitation of the extracted DNA (sensitivity, $10^{1}$ conidia) and the addition of $2 \mathrm{U} / 100 \mu \mathrm{l}$ lyticase (sensitivity, $10^{\circ}$ conidia). The addition of $\beta$ mercaptoethanol was not found to be beneficial with either method.

\section{Comparison using clinical samples (fig 2)}

The optimised TaKaRa based method (with additional lyticase and ethanol precipitation) was superior, with three of five samples positive after gel electrophoresis and all five after Southern blot hybridisation. This compares with one of five and four of five, respectively, with the optimised QIAamp based method.

\section{Specificity of the probe}

Using the high stringency hybridisation method described the probe was $100 \%$ specific for A fumigatus and A flavus.

\section{DISCUSSION}

Accurate diagnosis of IFIs is difficult and several methods have been developed in an attempt to speciate fungi causing invasive infection. The identification of fungi in tissue sections has been achieved by immunohistochemistry ${ }^{45}$ and in situ hybridisation. ${ }^{67}$ However, these techniques may not lead to species identification and are restricted to very few pathogens.

It has recently been shown that DNA can be extracted and amplified from fungal hyphae in fresh tissue ${ }^{8}$ or tissue that has been subjected to formalin fixation and paraffin wax embedding (B Willinger B, et al. Detection of aspergillosis of the maxillary sinus with molecular techniques, 2000. $6^{\text {th }}$ Congress of the European Confederation of Medical Mycology Societies. Abstract P4-002).

It is clear that these methods operate at the limits of detection in what may be very small samples, and so optimisation is important. We found that a method based on the TaKaRa DEXPAT kit, with the addition of lyticase and ethanol precipitation of extracted DNA, was more sensitive than one based on the QIAamp DNA mini kit. Using spiked samples it was possible to detect less than 10 conidia/sample, and a positive result was obtained with $100 \%$ of clinical samples known to be culture positive for A fumigatus.

"It is clear that these methods operate at the limits of detection in what may be very small samples, and so optimisation is important"

The high stringency Southern blot hybridisation technique described allowed accurate identification of $A$ fumigatus and A flavus. PCR products not hybridising with this probe could be identified using other species specific probes or by DNA sequencing. These methods will provide a valuable diagnostic tool for both patient management and future antifungal and epidemiological studies.

\section{ACKNOWLEDGEMENTS}

We are grateful to Ms L Boxer and the staff of the Pathology Department, Royal Free Hospital for cutting the tissue sections. Dr P J Paterson was supported by an educational grant from NexStar Pharmaceuticals.

\section{Authors' affiliations}

P J Paterson, S Seaton, C C Kibbler, Department of Medical Microbiology, Royal Free Hospital, Pond Street, London NW3 2QG, UK $J$ McLaughlin, Department of Pathology, Royal Free Hospital

This work was undertaken by Dr P J Paterson, Mrs S Seaton, Dr J McLaughlin, and $\operatorname{Dr}$ C C Kibbler with the Royal Free Hampstead NHS Trust who received a proportion of its funding from the NHS Executive; the views expressed in this publication are those of the authors and not necessarily those of the Trust or the NHS Executive.

Correspondence to: Dr C C Kibbler, Department of Medical Microbiology, Royal Free Hospital, Pond Street, London NW3 2QG, UK; kibbler@rfc.ucl.ac.uk

Accepted for publication 20 August 2003

\section{REFERENCES}

1 Perfect JR, Schell WA. The new fungal opportunists are coming. Clin Infect Dis 1996;22:S112-18.

2 Yeghen T, Kibbler CC, Prentice HG, et al. Management of invasive pulmonary aspergillosis in hematology patients: a review of 87 consecutive cases at a single institution. Clin Infect Dis 2000;31:859-68.

3 Einsele $\mathbf{H}$, Hebart $\mathrm{H}$, Roller $\mathrm{G}$, et al. Detection and identification of fungal pathogens in blood by using molecular probes. J Clin Microbiol 1997;35:1353-60.

4 Verweij PE, Smedts F, Poot $T$, et al. Immunoperoxidase staining for identification of aspergillus species in routinely processed tissue sections. J Clin Pathol 1996;49:798-801.

5 Kaufman L, Standard PG, Jalbert MK, et al. Immunohistologic identification of Aspergillus spp. and other hyaline fungi by using polyclonal fluorescent antibodies. J Clin Microbiol 1997;35:2206-9.

6 Park CS, Kim J, Montone KT. Detection of aspergillus ribosomal RNA using biotinylated oligonucleotide probes. Diagn Mol Pathol 1997;6:255-60.

7 Hanazawa R, Murayama SY, Yamaguchi H. In-situ detection of Aspergillus fumigatus. J Med Microbiol 2000;49:285-90.

8 Hendolin PH, Paulin L, Koukila-Kahkola P, et al. Panfungal PCR and multiplex liquid hybridisation for detection of fungi in tissue specimens. J Clin Microbiol 2000;38:4186-92. 